\title{
Nasopalatine duct cyst: A diagnostic dilemma
}

\author{
Modhi AlQahtani ${ }^{1}$, Ali AlDossari ${ }^{2}$, Ahmed Nasser ${ }^{3 *}$ and Khalid AlOtaibi ${ }^{4}$ \\ ${ }^{1}$ Bachelor of Dental Surgery, Princess Nourah Bint Abdulrahman University, King Abdullah bin Abdulaziz University Hospital, Riyadh, Saudi Arabia \\ ${ }^{2}$ Doctor of Medicine in Dentistry, Ministry of Health, Riyadh, Saudi Arabia \\ ${ }^{3}$ Bachelor of Dental Surgery, Oral and Maxillofacial department, King Abdulaziz Medical City, Ministry of National Guard Health Affairs, Riyadh, Saudi Arabia \\ ${ }^{4}$ Bachelor of Dental Surgery, Dental University Hospital, King Saud University Medical City, Riyadh, Saudi Arabia
}

\begin{abstract}
Nasopalatine duct cyst arises from embryologic remnants of nasopalatine duct. It is known to be the most frequently occurring non- odontogenic cyst of the oral cavity. The cyst is commonly asymptomatic and associated with swelling that usually located in the midline of anterior palate. This article reports a case in a $37-y e a r-$ old male patient with review of literature.
\end{abstract}

\section{Introduction}

The nasopalatine duct cyst was first described by Meyer in 1914 [1]. Other names were also used for the lesion such as maxillary midline cyst, anterior midline cyst, and incisive duct cyst and anterior middle palatine cyst. Nasopalatine duct cyst occurs in the median of the palate within the incisive canal, which is located in the palatine process, posterior to the alveolar process of the upper maxillary central incisors. The World Health Organization classified the nasopalatine duct cyst as a developmental, epithelial, non-odontogenic cyst of the maxilla. The duct is known to regress in fetal life, however the persistence of ductal epithelium leads to cyst formation. As it is considered to be the most common non-odontogenic cyst of the gnathic bones [2]. The mean medio-lateral diameter of the incisive foramen ranged from $1.40 \mathrm{~mm}$ to $5.90 \mathrm{~mm}$ [3], cysts larger than the normal anatomical feature can only be distinguished from incisive foramen. NPDC's are asymptomatic and usually detected as an incidental finding, however it may cause swelling in the anterior part of the hard palate. Teeth vitality are not affected by NPDC, however it is common to see evidence of root canal treatment when NPDC's are misinterpreted as a periapical lesion $[4,5]$.

\section{Case report}

A 37-year-old male patient presented to a dental clinic. The patient's main complaint was painless swelling on the anterior palate, However the patient reported a pressure over the anterior maxilla. Clinical examination showed a swelling in the anterior palate, it was round in shape fluctuant and non-tender, while no teeth discoloration of the was noted (Figure 1). Orthophantomogram showed a well-defined, ovoid unilocular radiolucency, localized in the anterior maxilla apical to teeth $\# 13,12,11,21$ with involvement of the teeth apical third and extending from distal of tooth \#13 to the distal of tooth \#21 (Figure 2). Periapical radiograph of teeth \#11,12, 13 and 21 revealed a welldefined corticated unilocular radiolucency apical to teeth \#11, 12, 21 with widening of periodontal ligament space of tooth \#12 and 21 , root resorption was evident without displacement in teeth \#12,11,21 (Figure 3). A cone-beam computed tomography (CBCT) scan taken (Planmeca ProMax 3D; Planmeca OY, Helsinki, Finland) to the anterior maxilla showed a well-defined radiolucency in the region of nasopalatine canal with noticeable thinning and subsequent eroded palatal and buccal cortical bone in the sagittal sections and 3D rendered image (Figure 4). Endodontic examination and diagnosis of the involved teeth are listed in (Table 1). Provisional diagnosis of nasopalatine duct cyst was established. Fine needle aspiration cytology revealed brownish color aspirate and no purulent discharge material was evident which showed no evidence of malignancy. Based on clinical examination, radiological and histopathological investigations, a diagnosis of nasopalatine duct cyst was considered. Root canal treatment of teeth \#11,12 was done (Figure 5). and surgical enucleation of the cyst was planned via a buccal approach through the eroded buccal bone. Upon reflection of a fullthickness mucoperiosteal flap, the cystic lesion was located between the apices of teeth number \#11 and \#12 (Figure 6). The surgically enucleated lesion was dissected and submitted for histologic examination while the root apexes of teeth \#11, 12 were resected and mineral trioxide aggregate (MTA) was placed as a retrograde filling (Figure 7). Root canal treatment was initiated and completed for teeth \#13, 21 (Figure 8). The finale oral pathology report confirmed an NPDC as the final diagnosis (Figure 9). There was evidence of bone regeneration in the follow up visit at 6 months (Figure 10).

\section{Discussion}

Nasopalatine duct cysts are developmental, epithelial, nonneoplastic, non-odontogenic cysts and known to be the most common type of non-odontogenic cysts [7]. the epithelial lining in the nasopalatine canal is believed to degenerate; however, in some cases it embryonic tissue persists and proliferates to form a cyst in the midline of the anterior palate [8]. The majority cases of the nasopalatine duct cyst are asymptomatic and diagnosed as an incidental finding during routine dental examination between the fourth and sixth decades of life, however if the nasopalatine duct cyst became large, it can cause painless

${ }^{\star}$ Correspondence to: Ahmed Essam Nasser, Bachelor of Dental Surgery, Oral and Maxillofacial department, King Abdulaziz Medical City, Ministry of National Guard Health Affairs, Riyadh, Saudi Arabia,

Key words: nasopalatine duct cyst, non-odontogenic cyst, incisive canal cyst, median palatine cyst

Received: April 01, 2018; Accepted: April 19, 2018; Published: April 23, 2018 
Table 1. Endodontic examination and diagnosis

\begin{tabular}{|c|c|c|c|c|c|c|}
\hline Teeth & Cold test & EPT & Percussion & Palpation & Probing & Radiograph \\
\hline 13 & + & + & $\mathrm{N}$ & $\mathrm{N}$ & $<3 \mathrm{~mm}$ & - uniform periodontal membrane space \\
\hline 12 & - & - & $\mathrm{N}$ & $\mathrm{N}$ & $<3 \mathrm{~mm}$ & $\begin{array}{l}\text { - lack of continuity of the Lamina dura } \\
\text { - Apical external root resorption }\end{array}$ \\
\hline 11 & - & - & $\mathrm{N}$ & $\mathrm{N}$ & $<3 \mathrm{~mm}$ & $\begin{array}{l}\text { - uniform periodontal membrane space } \\
\text { - Apical external root resorption }\end{array}$ \\
\hline 21 & - & - & $\mathrm{N}$ & $\mathrm{N}$ & $<3 \mathrm{~mm}$ & $\begin{array}{l}\text { - lack of continuity of the Lamina dura } \\
\text { - Apical external root resorption }\end{array}$ \\
\hline 22 & + & + & $\mathrm{N}$ & $\mathrm{N}$ & $<3 \mathrm{~mm}$ & - uniform periodontal membrane space \\
\hline \multicolumn{5}{|c|}{ Endodontic diagnosis: } & \multirow{5}{*}{$\begin{array}{l}\mathrm{N}: \text { Normal } \\
-: \text { No response }\end{array}$} & \\
\hline 13: & \multirow{2}{*}{\multicolumn{4}{|c|}{ Necrotic pulp, Asymptomatic apical periodontitis }} & & \\
\hline 12: & & & & & & \\
\hline 11: & \multicolumn{4}{|c|}{ Necrotic pulp, Normal apical area } & & \\
\hline 21: & \multicolumn{4}{|c|}{ Necrotic pulp, Asymptomatic apical periodontitis } & & \\
\hline
\end{tabular}

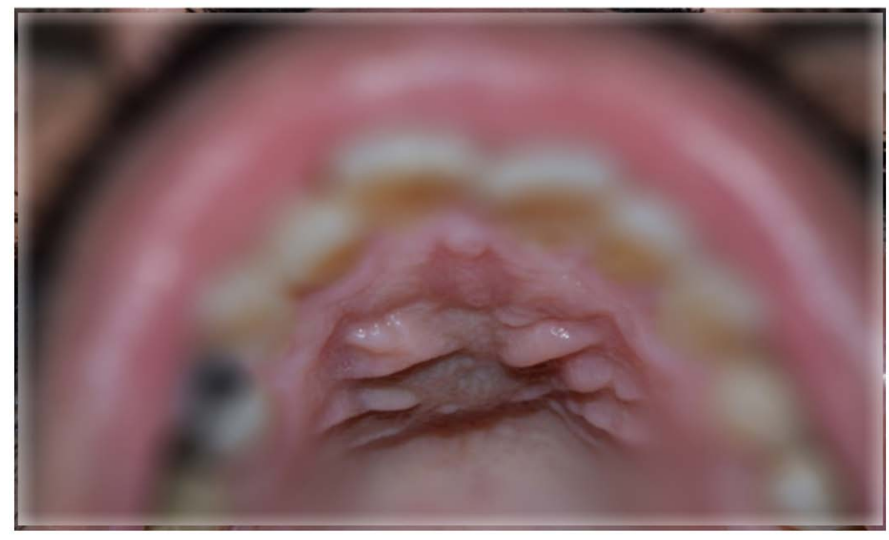

Figure 1. Intraoral photograph showing the swelling on the anterior palate

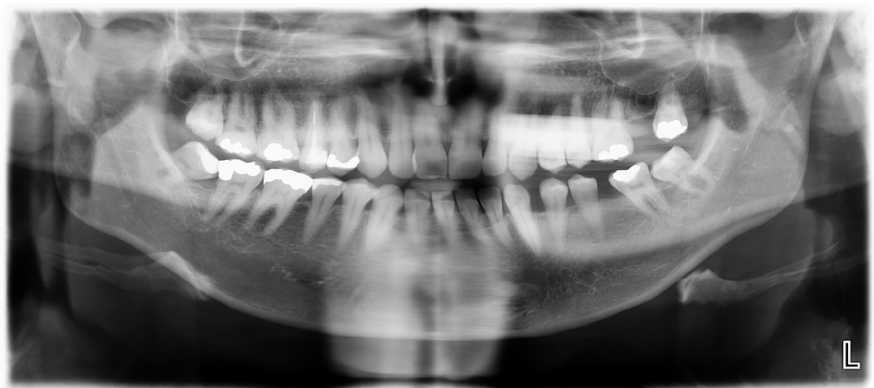

Figure 2. Preoperative panoramic radiograph demonstrating the radiolucency at the upper maxillary midline

swelling in the midline of the anterior palate, and sometimes associated with burning sensation. The burning sensation can develop due to the pressure on the nasopalatine nerve [9]. Intraoral periapical radiograph can reveal a heart-shaped radiolucency due to the superimposition of the anterior nasal spine, superimposition of the cystic lesion and the anterior teeth can cloud the judgment leading to misdiagnosis of nasopalatine cyst if endodontic examination haven't done properly or not at all, moreover most of the reported cases of misdiagnosis were initially treated by general dentists [10-15]. A positive response to vitality tests in the involved teeth should indicate a lesion of nonodontogenic origin, yet if the vitality test gave a negative response or endodontic therapy has been initiated or completed, establishing the differential diagnosis becomes clouded. Although Tsuneki M et al. [16] reported in his clinicopathological study of 41 cases of nasopalatine duct cyst that half of the teeth associated with the cysts $(9 / 18$ cases,

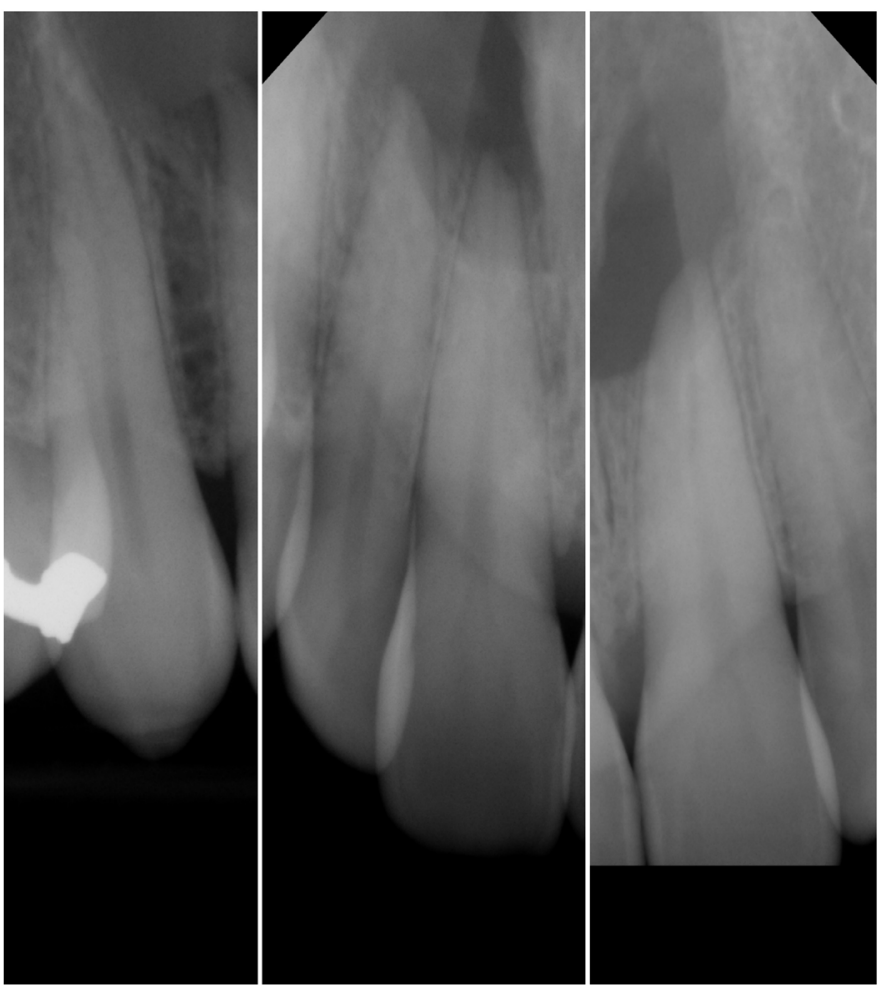

Figure 3. Intraoral periapical radiograph showing well-defined round radiolucency in befween the roots of the maxillary anterior teeth with noticeable root resorption were determined to be non-vital by electric pulp tests. When the cyst is located at a higher level in the nasopalatine duct, its effect on the teeth are lessen, while the lower its located in the nasopalatine duct, the higher the risk of teeth displacement or root resorption $[17,18]$. non-odontogenic cysts may produce different patterns of external root resorption, Inflammatory conditions and mechanical stimulation can cause an external root resorption [19]. The periapical replacement resorption is the replacement of the resorbing root with bone, while the pathologic entities causing root resorption can destruct the bone and the tooth, resulting in cavitation [20].

\section{Conclusion}

In the case of asymptomatic apical radiolucency located in the anterior maxilla associated with an initiated or completed root canal therapy, and when nasopalatine duct cyst is suspected, taking an 

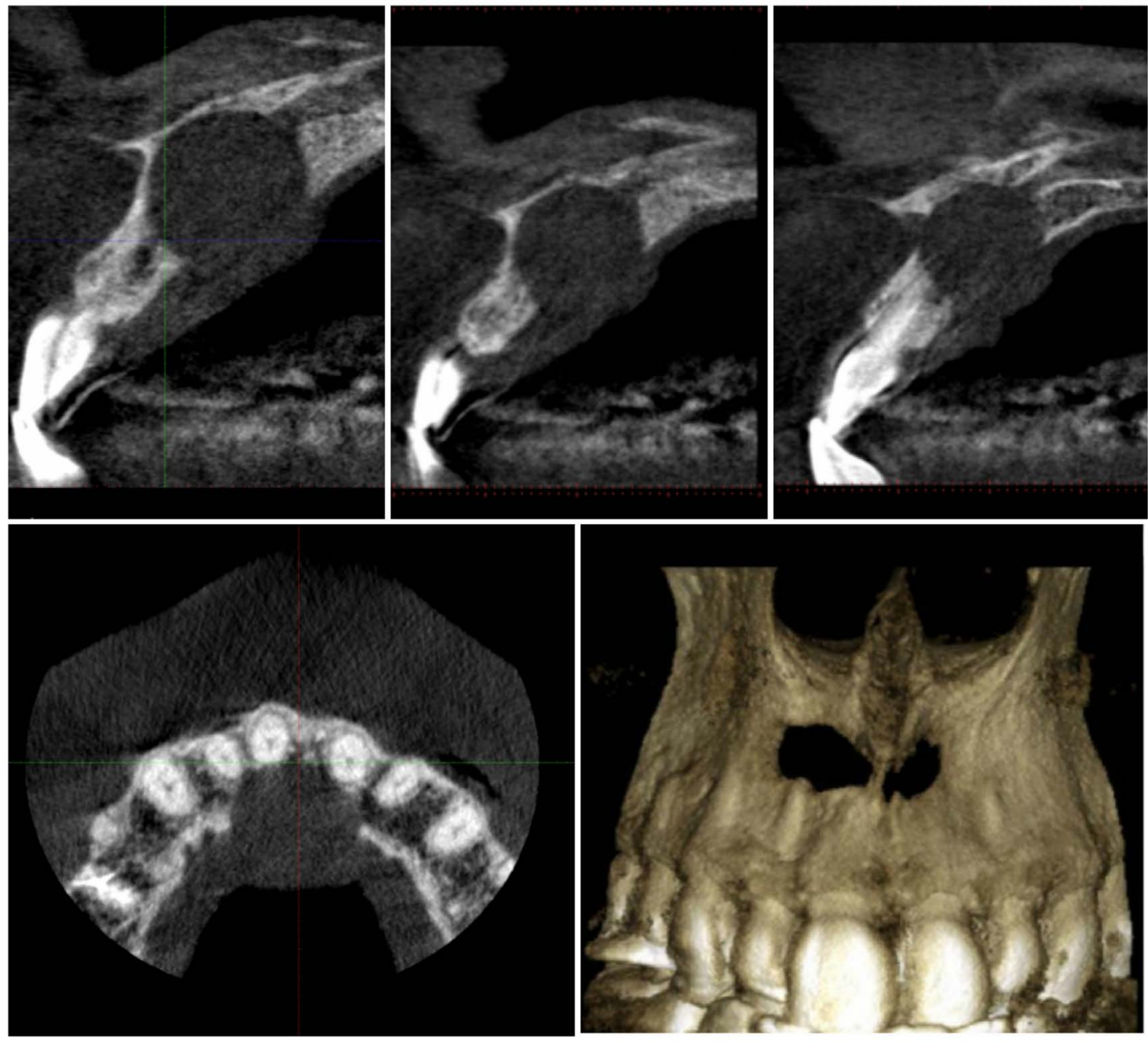

Figure 4. Cone beam computed tomography (CBCT), axial and sagittal views demonstrating the radiolucency at the upper maxillary midline

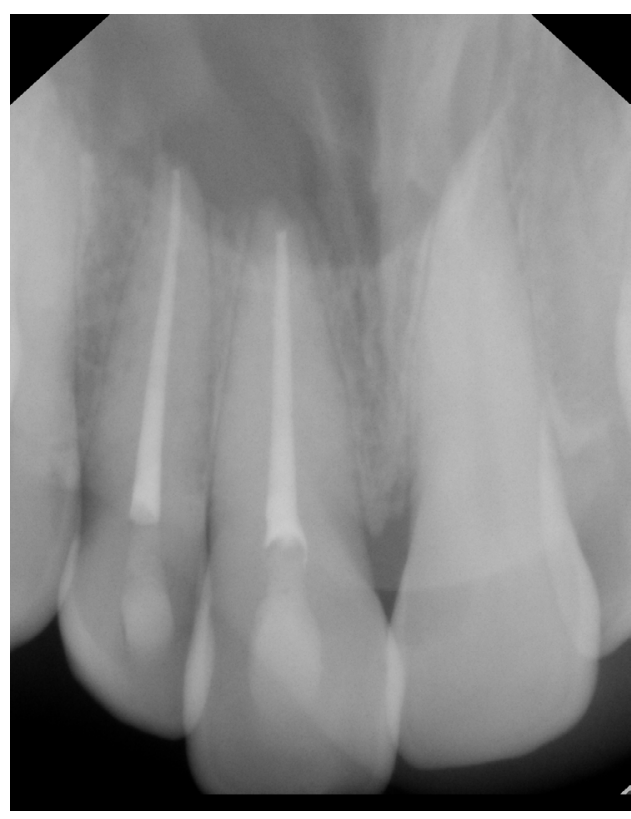

Figure 5. Postoperative periapical radiographs of teeth \#11, 12

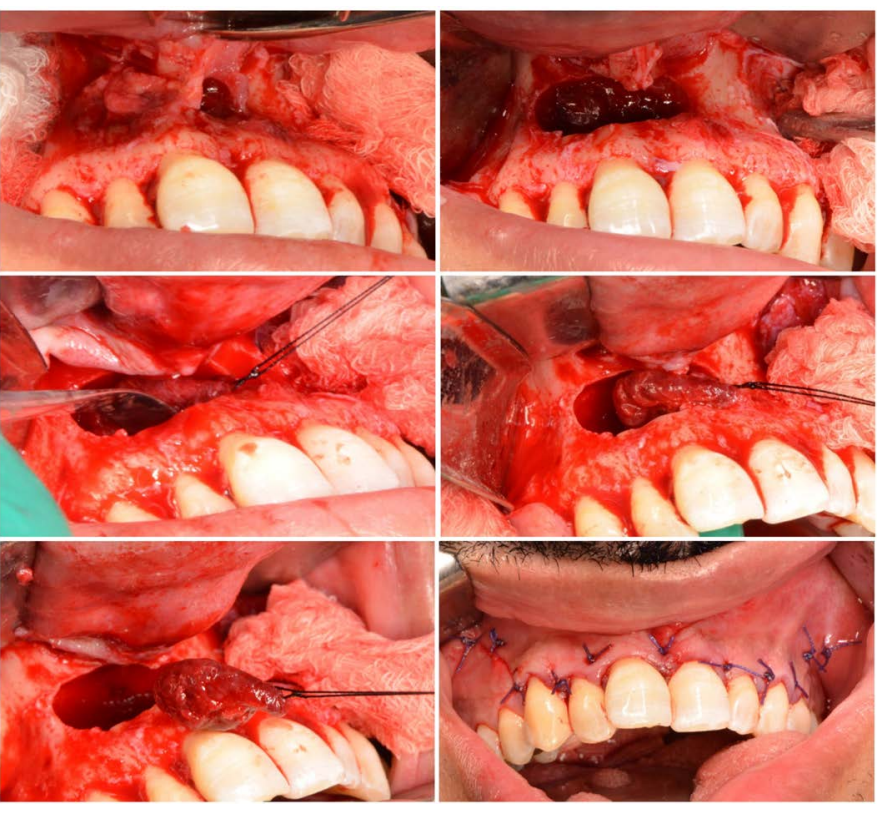

Figure 6. Intraoperative views of the cyst enucleation procedure 


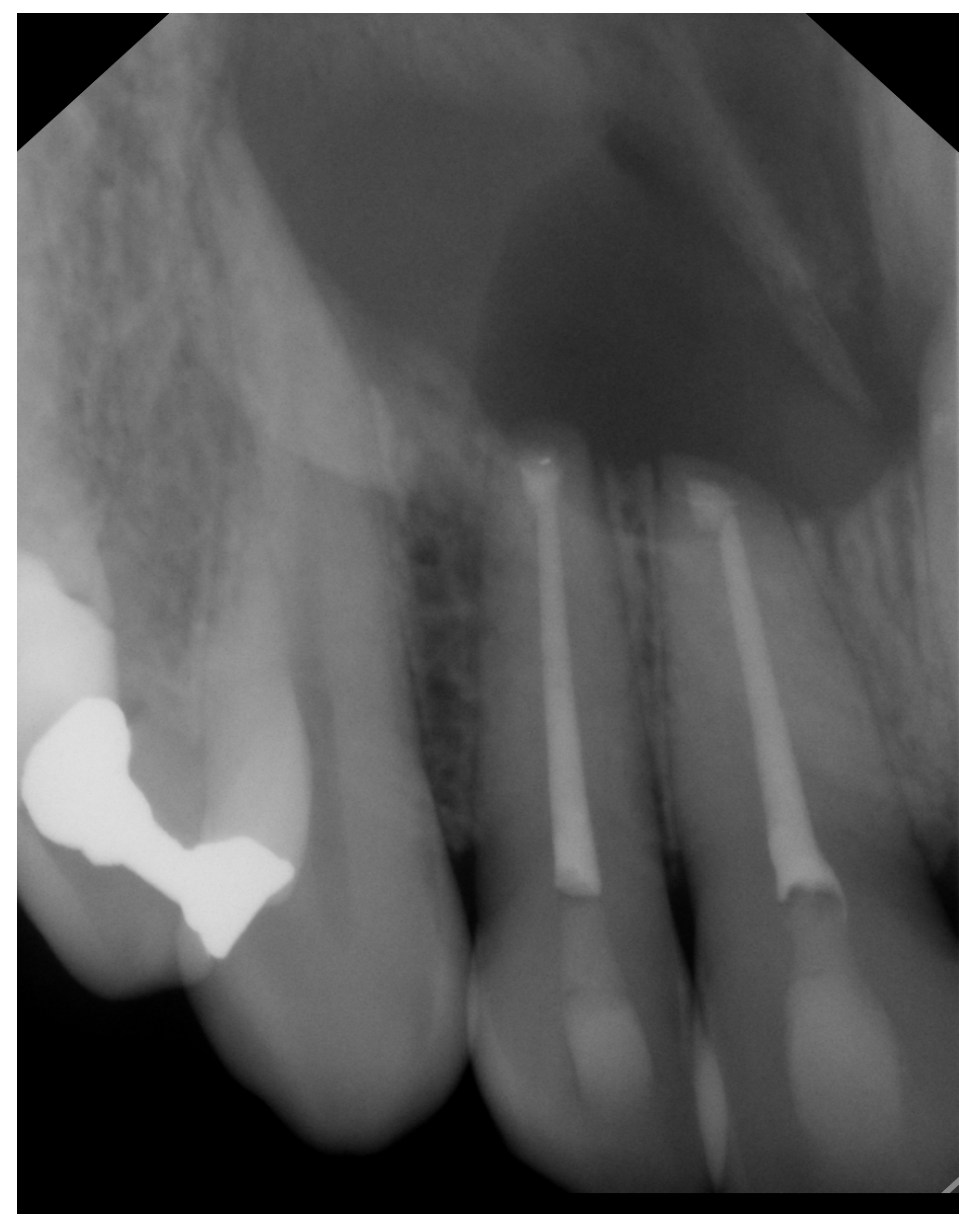

Figure 7. Postoperative periapical radiograph showing a retrograde filling in teeth \#11 and 12

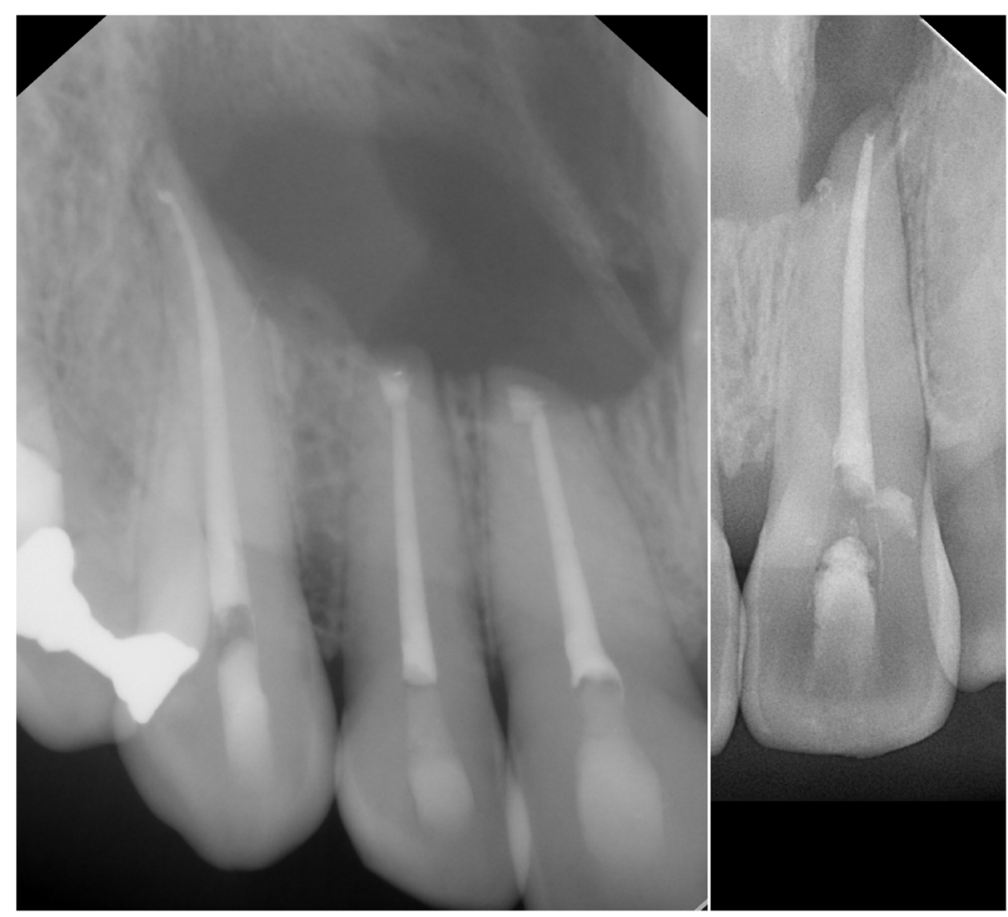

Figure 8. Postoperative periapical radiographs showing the root canal treatment of teeth \#13 and 21 


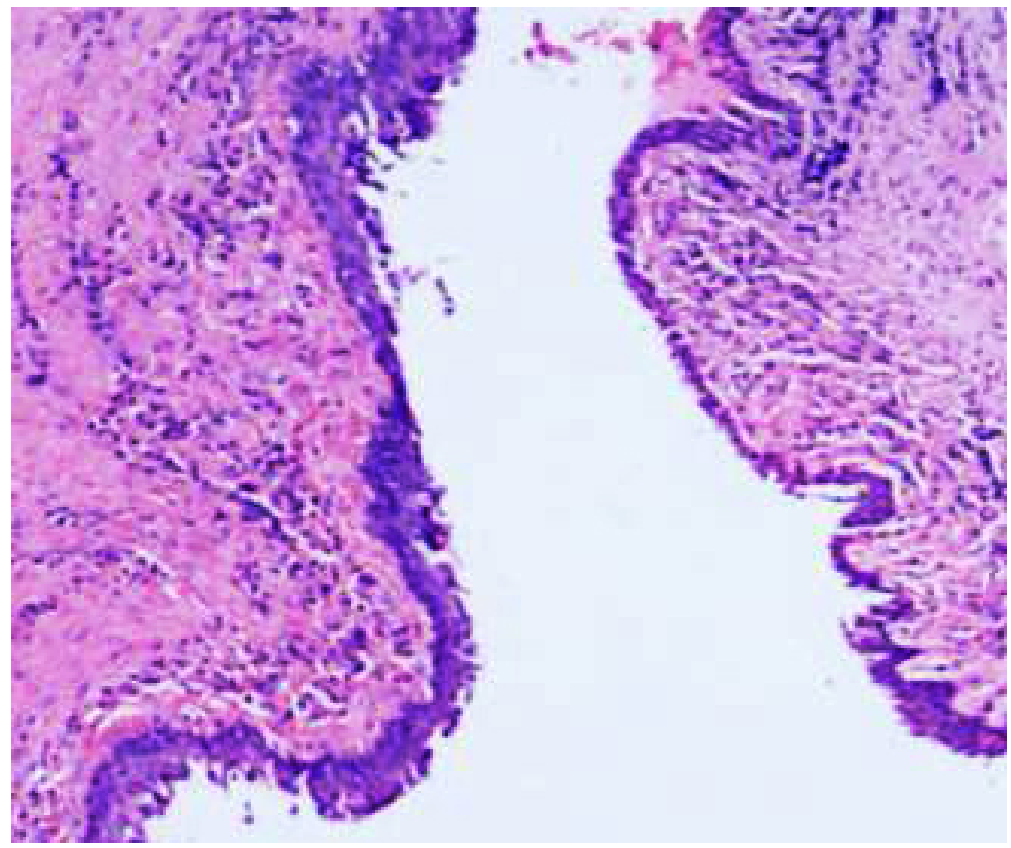

Figure 9. Histopathologic examination of the excised specimen showed the cyst wall lined with stratified squamous epithelium
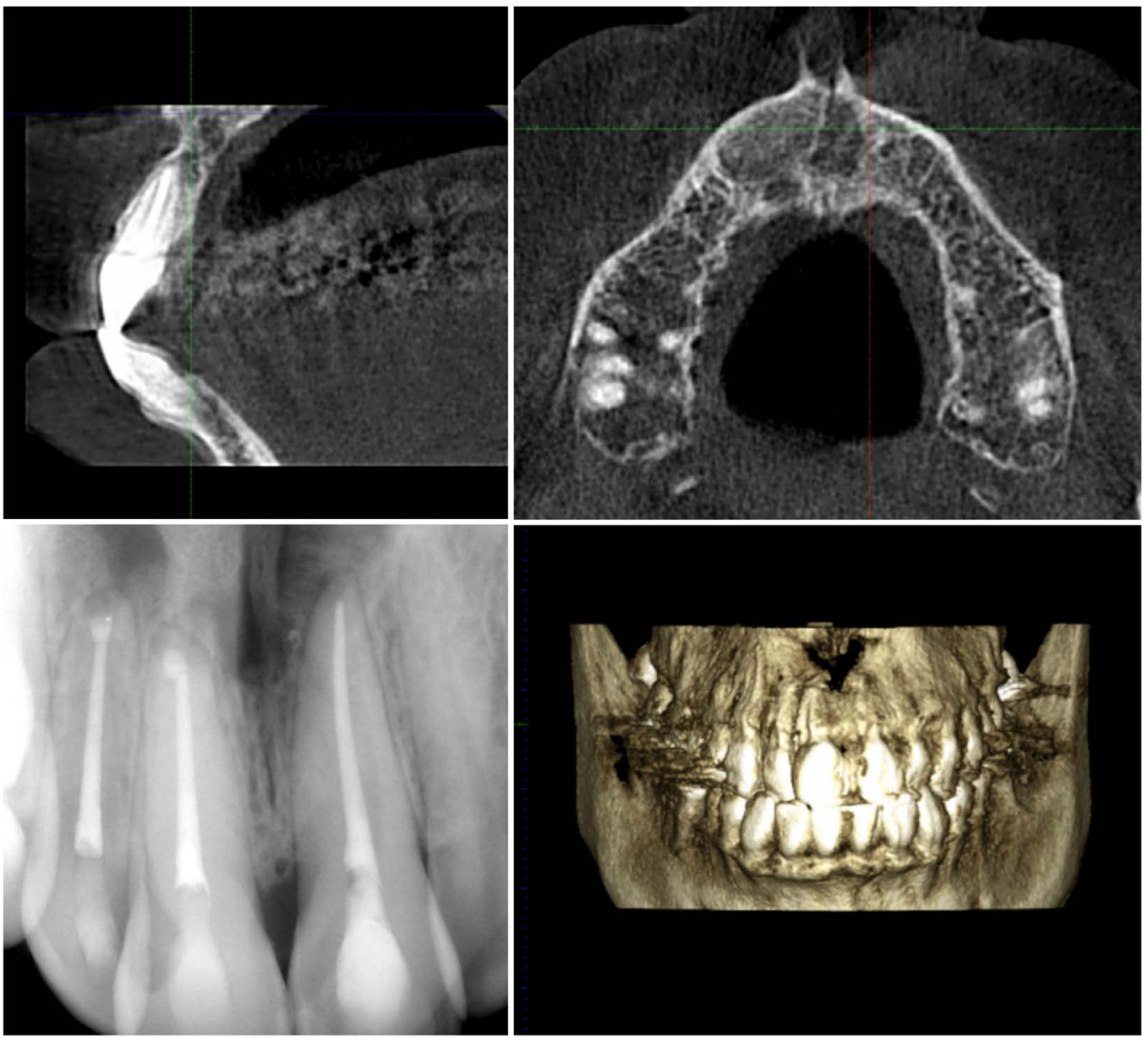

Figure 10. A 6-months postoperative radiograph showing adequate healing and bone formation 
occlusal radiograph or a second periapical radiograph using tube shift technique (Clark's rule) is likely to be a useful aid in differential diagnosis by locating the lesion.

\section{Conflicts of interest}

There are no conflicts of interest.

\section{References}

1. Meyer AW (1914) A unique supernumerary paranasal sinus directly above the superior incisors. J Anato My 48: 118-129.

2. Butt FMA, Ogeng'O J, Bahra J, Chindia ML (2011) Pattern of odontogenic and nonodontogenic cysts. J Craniofac Surg 22: 2160-2162. [Crossref]

3. Thakur AR, Burde K, Guttal K, Naikmasur VG (2013) Anatomy and morphology of the nasopalatine canal using cone-beam computed tomography. Imaging Sci Dent 43: 273. [Crossref]

4. Faitaroni LA, Bueno MR, Carvalhosa AA, Mendonça EF, Estrela C (2011) Differential diagnosis of apical periodontitis and nasopalatine duct cyst. J Endod 37: 403-410. [Crossref]

5. Terry BR, Bolanos OR (1989) A diagnostic case involving an incisive canal cyst. $J$ Endod 15: 559-562.

6. Arx TV, Lozanoff S (2016) Nasopalatine Canal. Clinical Oral Anatomy Jun:103-131.

7. Swanson KS, Kaugars GE, Gunsolley JC (1991) Nasopalatine duct cyst: An analysis of 334 cases. J Oral Maxillofacial Surg 49: 268-271. [Crossref]

8. Gnanasekhar JD, Walvekar SV, Al-Kandari AM, Al-Duwairi Y (1995) Misdiagnosis and mismanagement of nasopalatine duct cyst and its corrective therapy. A case reports. Oral Surg Oral Med Oral Pathol Oral Radiol Endod 80: 465-470. [Crossref]

9. Francoli JS, Marques NA, Aytis LB, Escoda CG (2008) Nasopalatine duct: report of 22 cases and review of literature. Med Oral Patol Oral Cir Bucal 13: E438-E443. [Crossref]
10. Faitaroni LA, Bueno MR, Carvalhosa AA, Mendonça EF, Estrela C (2011) Differential diagnosis of apical periodontitis and nasopalatine duct cyst. $J$ Endod 37: 403-410. [Cossref]

11. Gulabivala K, Briggs PFA (1992) Diagnostic dilemma: an unusual presentation of an infected nasopalatine duct cyst. International Endodontic Journal 25: 107-111. [Cossref]

12. Kuc I, Peters E, Pan J (2000) Comparison of clinical and histologic diagnoses in periapical lesions. Oral Surgery, Oral Medicine, Oral Pathology, Oral Radiology, and Endodontology 89: 333-337.

13. Ortega A, Fariña V, Gallardo A, Espinoza I, Acosta S (2007) Nonendodontic periapical lesions: a retrospective study in Chile. Int Endod J 40: 386-390. [Crossref]

14. Suter VG, Büttner M, Altermatt HJ, Reichart PA, Bornstein MM (2011) Expansive nasopalatine duct cysts with nasal involvement mimicking apical lesions of endodontic origin: A report of two cases. J Endod 37: 1320-1326. [Crossref]

15. Terry BR, Bolanos OR (1989) A diagnostic case involving an incisive canal cyst. $J$ Endod 15: 559-562. [Crossref]

16. Tsuneki M, Maruyama S, Yamazaki M, Abé T, Adeola H, et al. (2012) Inflammatory histopathogenesis of nasopalatine duct cyst: a clinicopathological study of 41 cases. Oral Dis 19: 415-424. [Crossref]

17. McCrea SJ (2012) Nasopalatine Duct Cyst, a delayed complication to successful dental implant placement: Diagnosis and surgical management. J Oral Implantol 40: 189-95. [Crossref]

18. Sankar D, Muthusubramanian V, Nathan J, Nutalapati R, Jose Y, et al. (2016) Aggressive nasopalatine duct cyst with complete destruction of palatine bone. J Pharm Bioallied Sci 8: 185. [Crossref]

19. Fuss Z, Tsesis I, Lin S (2003) Root resorption - diagnosis, classification and treatment choices based on stimulation factors. Dent Traumatol 19:175-182. [Crossref]

20. Bender I, Byers MR, Mori K (1997) Periapical replacement resorption of permanent, vital, endodontically treated incisors after orthodontic movement: Report of two cases. J Endod 23: 768-773. [Crossref]

Copyright: (C2018 AlQahtani M. This is an open-access article distributed under the terms of the Creative Commons Attribution License, which permits unrestricted use, distribution, and reproduction in any medium, provided the original author and source are credited. 